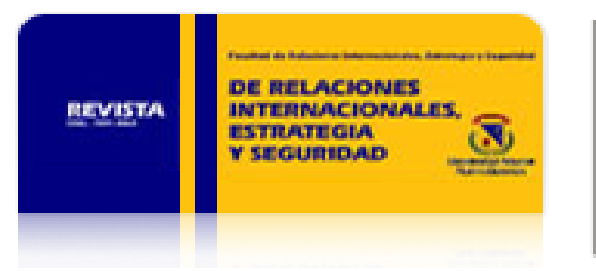

Revista de Relaciones Internacionales, Estrategia y Seguridad

ISSN: 1909-3063

cinuv.relinternal@unimilitar.edu.co

Universidad Militar Nueva Granada

Colombia

Ghotme, Rafat

Orden, Des-Orden y Antiorden Mundial. Problemas de Relaciones Internacionales Revista de Relaciones Internacionales, Estrategia y Seguridad, vol. 1, núm. 2, julio-diciembre, 2006,

pp. 75-703

Universidad Militar Nueva Granada

Bogotá, Colombia

Disponible en: http://www.redalyc.org/articulo.oa?id=92710205

- Cómo citar el artículo

- Número completo

- Más información del artículo

- Página de la revista en redalyc.org

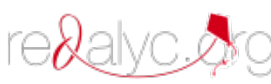

Sistema de Información Científica

Red de Revistas Científicas de América Latina, el Caribe, España y Portugal Proyecto académico sin fines de lucro, desarrollado bajo la iniciativa de acceso abierto 


\title{
ORDEN, DES-ORDEN Y ANTIORDEN MUNDIAL Problemas de Relaciones Internacionales
}

\author{
Por: Rafat Ghotme ${ }^{1}$
}

\section{RESUMEN}

En este ensayo se tratarán las relaciones internacionales como un sistema en el cual, interactúan diversos órdenes que evolucionan de forma sistemática. Un orden mundial se construye con el paso de la historia. Esto significa que las relaciones internacionales, como disciplina científica, se fundamentan en una presunción moderna de la era del capital y las subsecuentes etapas de la industrialización, las telecomunicaciones, el imperialismo y la preponderancia de las naciones-estado

1 Internacionalista e historiador. Docente investigador del programa de Relaciones Internacionales y Estudios Políticos de la Universidad Militar Nueva Granada. 
REVISTA DE RELACIONES INTERNACIONALES, ESTRATEGIAYSEGURIDAD

que configuran el actual orden como la fase más avanzada de esta era. La idea cardinal de este trabajo es que el actual orden mundial es una secuencia de diversos sistemas históricos que han evolucionado hasta convertirse en lo que es la Sociedad Internacional contemporánea. En ese sentido, un orden mundial se construye como parte de una política deliberada de las grandes potencias, condicionadas por la guerra y la paz. Por lo general, dentro de sus propósitos tiene actuaciones de tipo geopolítico, diplomático, económico, tecnológico e ideológico. Además de sus ciclos de desarrollo, crisis, decadencia y transición de los valores cristalizados en la Sociedad Internacional, en la misma medida que decaen o se desarrollan estos valores, se expresan nuevas o viejas potencias con sus respectivos mecanismos de política exterior. La matriz universal del sistema reposa sobre la misión de civilizar a los pueblos que no están al abrigo del orden. Mas un tipo de Sociedad Internacional dominante choca permanentemente con los distintos tipos de culturas o nacionalismos imperantes en una época. Un continuo caos y desorden rechina a los organizadores del orden, en la medida en que tratan de transmitir valores internacionales dentro de un marco cultural deforme. El sistema internacional, en sentido histórico, sirve entonces como referente para el estudio de las relaciones internacionales, compararlas entre sí y generar un cuerpo de significantes reales que se pueden demostrar empíricamente. Emite un patrón general de relaciones que configuran un orden, en un escenario general donde se suceden los fenómenos internacionales.

\section{Palabras claves}

Orden Mundial, Des orden Mundial, Antiorden Mundial, Historia de las Relaciones Internacionales, Sociedad Internacional, Imperio, Imperialismo, Grupos Sociales Internacionales, Nacionalismos, Choque de Civilizaciones, Yugoslavia, Palestina, Israel, Afganistán, Irak, Asia Central, América Latina, Estados Unidos, Unión Europea.

\section{ABSTRACT}

In this essay the international relations like a system will be approached where diverse orders interact that evolve of systematic form. A world order is constructed historically. This indicates that the international relations, like scientific discipline, are based on a modern presumption of the era of the 
capital and the subsequent stages of industrialization, the telecommunications, the imperialism and the superiority of nation-Estates, forming the present order like the phase more outpost of this stage. The cardinal idea of this work is the one of which the present world order is a sequence of diverse historical systems that evolved until becoming which is the International Society contemporary. In that sense, a world order is constructed like part of a deliberate policy of the great powers, conditional by the war and peace. It generally has within his intentions performances of geopolitical, diplomatic, economic, technological and ideological type. In addition to their development cycles, crises, decay and transition of the values crystallized in the International Society, in the same measurement that decay or these values are developed express new or old powers with their respective mechanisms of foreign policy. The universal matrix of the system rests on the mission to civilize the towns that are not to the lee of the order. But a type of International Society that it dominates hits the different types from cultures or prevailing nationalisms at a time permanently. A permanent chaos and disorder squeak to the organizers of the order in the measurement who try to transmit international values within a deformed cultural frame. The international system, in historical sense, serves as referring in the study of real significant the international relations to compare them to each other and to generate a body of empirically demonstrable. It emits a general pattern of relations that are components of an order, in a general scene where the international phenomena follow one another.

\section{Key words}

World order, World-wide Disorder, World-wide Antiorder, History of the International Relations, International Society, Empire, Imperialism, International Social Groups, Nationalisms, Shock of Civilizations, Yugoslavia, Palestine, Israel, Afghanistan, Iraq, Central Asia, Latin America, United States, European Union. 
Existen dos imágenes convencionales sobre la era posterior a la guerra fría: la primera muestra el inicio de un Nuevo Orden, en el cual, Estados Unidos emerge victorioso en el sistema internacional y emprende una carrera para colocarse a la cabeza de la civilización occidental y el derecho internacional; la segunda insiste en que tal hegemonía no es más que una broma pesada de Bush padre, una era de incertidumbre, de caos y que por el contrario, es la fase de declinación norteamericana con un espectro futurista muy oscuro. A partir de la década de 1990, este panorama indujo a algunos a reconocer que "un cambio de proporciones gigantescas se viene fraguando en el sistema histórico-social que dio lugar al mundo moderno" (Arrighi y Silver et al. 2001:9), pero que a diferencia de lo que aducirían Hobsbawm (1994), o Wallerstein (1996), no marcan el final de una era inaugurada en el largo siglo XVI e institucionalizado por la Ilustración y la Revolución Francesa. Más aún, una constelación de las dos imágenes decantó en lo que Giddens o Callinicos (2002), atribuyeron a una Tercera Vía que combinaba los elementos de la vieja democracia social (Estado benefactor), y el neoliberalismo (libre mercado y Consenso de Washington), pero que al fin de cuentas, idealizaba el triunfo virtual de las ideologías occidentales. Una falta de consenso sobre los actuales parámetros de la economía política global además, dificulta la comprensión de los cambios sistemáticos que se vienen produciendo desde las décadas de 1970 y 1980, que desembocaron en la bifurcación (resquebrajamiento o regularidades), del sistema del mundo moderno (Wallerstein, 2004; Arrighi y Silver et al. 2001).

La interpretación de la formación o reestructuración de un orden supone entonces, un debate acerca de diversos componentes del sistema internacional, asumida bajo la óptica de la Teoría del Caos y del sistema internacional ${ }^{2}$.

${ }^{2}$ En todo sistema, desde Poincaré, subyacen elementos (exógenos o endógenos a él), que determinan su existencia, desarrollo y dinamismo. Tales elementos suelen ser perdurables en

ORDEN, DES-ORDEN Y ANTIORDEN MUNDIAL. Problemas de Relaciones Internacionales 
Dentro de estos componentes sobresalen al menos tres: 1. La hegemonía en el sistema mundial; 2. La reconfiguración parcial o total del capital en función del Estado moderno, la empresa y los trabajadores; y 3. Las transiciones de hegemonía entre las diversas civilizaciones que ocupan un lugar preponderante en el sistema (Arrighi y Silver et al. 2001; Wallerstein, 1996). Según Wallerstein $(1996,2004)$, estos tres componentes están pasando por un momento de bifurcación (caos), del sistema que supone la permanencia de algunas regularidades (guerras y preponderancia del Estado nación), y de caos (criminalidad, conflictos étnicos y la transición de la hegemonía norteamericana). Wallerstein (1998:35), sin embargo, cuando dice que "estamos viviendo el tránsito de nuestro sistema mundial vigente, la economía-mundo capitalista, a otro u otros sistemas mundiales", deja en entredicho la preponderancia del Estado nación, y más aún, admite que su fracaso en la esfera de lo social, abre el camino para cambiar o buscar alternativas históricas de cambio. La transición de la hegemonía -norteamericana en este caso-, tiene incrustada la probabilidad de que el "estado-nación moderno, ese artefacto de los siglos XVIII y XIX, ha empezado a venirse abajo" (Ohmae, 1997:21). Si bien las transiciones de hegemonía histórico-sociales que se han suscitado desde el siglo XVII (holandesa, francesa o británica), han demostrado que en sus interludios, el Estado nacional se ha mantenido -y en algunos casos reforzado-, qué haría pensar que aquello que Wallerstein Ilama transiciones a uno u otro sistema, desembocaría en la posible desaparición del Estado nación moderno. Más aún, mientras que en los siglos XVIII, XIX y buena parte del XX (hasta 1970-1990), a la potencia hegemónica le interesaba mantener el status de estados nacionales a sí mismos y a las periferias, en nombre del desarrollismo (1950-1970), la autodeterminación nacional (1945-1960), o el estado de bienestar (1960). A partir de 1990, el Estado nacional comienza a ceder paso a unidades geográficas confusas y extravagantes. Estas unidades geográficas, los Estados-región, según Ohmae (1997:109-110), son las nuevas "líneas divisorias" con sentido y que ayudan a comprender el sistema internacional en tiempos de caos e incertidumbre. A falta de una hegemonía, continúa Ohmae (1997), los Estados-región se adaptan con rapidez a la lógica mundial o a "la trayectoria positiva del crecimiento".

el tiempo y en la medida en que se modifican (caos-resquebrajamiento-transición), también permanecen pululando algunos de los elementos "viejos" (regularidades), que o bien se transforman (pero mantienen su esencia), o bien perduran (Arrighi y Silver et al. 2001:29; Wallerstein, 2004:412 ss; Abu Lughod, 1989: 368-369). 
REVISTA DE RELACIONES INTERNACIONALES, ESTRATEGIAY SEGURIDAD

Lo cierto es que para Ohmae (1997:118), en la actual coyuntura de caos del sistema internacional, el Estado nacional, a diferencia del regional, no va impulsar el crecimiento económico (si se parte del hecho que éste se creó para tales fines). En el fondo del debate, se centra la cuestión crucial de las economías emergentes del Lejano Oriente. A lo cual los idealistas norteamericanos Ilamaron "choque de civilizaciones" o el "fin de la historia", presupuso el temor por la posible expansión china en la era posmaoísta. Dicho en pocas palabras, una nueva guerra fría que tomaría posición en varios frentes: mayor cooperación entre las potencias occidentales y el destino del utillaje militar mediante una remozada OTAN (que en el fondo demostró el temor de Estados Unidos a una nueva fuerza unificada de la Unión Europea) ${ }^{3}$. En ambos casos, sin embargo, se desconocen diversos factores históricos tales como la continua y expansiva relación entre Oriente y Occidente desde el siglo XIII (o mejor desde el XVI), como "fuerza de arrastre" en la conformación del sistema de economía mundial (Arrighi y Silver et al. 2001; Abu Lughod, 1989), por una parte, y los interludios que existen entre los períodos de caos, transición y desarrollo de un orden o sea, en los momentos cuado se reconfiguran las relaciones entre las unidades del sistema (Arrighi y Silver et al. 2001), por la otra parte. En síntesis, la transición de hegemonía de un Estado nación a otro u otro sistema (v. gr. Estado región), de una civilización a otra o simplemente a otros Estados o Corporaciones (globalización), es un hecho real que demuestra la falta de consenso sobre la dirección del actual sistema internacional.

De tal situación se desprende un no menos importante aspecto crucial. Si bien el Estado nacional cumplió los requerimientos de la clase trabajadora en Occidente y en otros lugares, ¿qué lugar ocuparían las multitudes en una era de caos y donde aparentemente el Estado nacional ya no tendría la misma preponderancia para ellos? Por lo general, este debate hace parte de lo que comúnmente se conoce como globalización. La creciente volatilidad del capital y su subsecuente movilidad geográfica está provocando lo que Arrighi y Silver (2001), Ilamaron una "carrera hacia el abismo"

\footnotetext{
${ }^{3}$ La evidencia que arroja la historia demostró contundentemente que el choque preconizado por Huntington se encuentra en desuso. Si han existido conflictos internacionales, éstos se corresponden a otros fenómenos, menos a los intercivilizadores. Los nacionalismos, las cuestiones coloniales y neocoloniales, la geopolítica moderna y contemporánea dan cuenta de manera más clara de los conflictos internacionales. La teleología de Huntington se ensancha por ser ahistórica.
}

ORDEN, DES-ORDEN Y ANTIORDEN MUNDIAL. Problemas de Relaciones Internacionales 
de los salarios y las condiciones de seguridad social del trabajador. Wallerstein (1996, 2004), se fue lanza en ristre contra el liberalismowilsoniano (Estado de bienestar), la fulgurante geocultura del mundo durante más de un siglo, para decir que era la oportunidad histórica de los movimientos antisistémicos en la conformación de un mundo más justo y equitativo. Tales movimientos que Hardt y Negri (2000), condensaron en las multitudes, atacarían el sistema desde sus entrañas. Esto indica por una parte, que si bien el socavamiento del Estado nacional es evidente, se debe más bien a una nueva organización social del capital (altas finanzas), que a su vez condiciona la creación de una clase obrera internacional con nuevos derechos y deterioro de los viejos (Arrighi y Silver et. al. 2001). Pero, paradójicamente, da lugar a una nueva clase de conflictos que mezcla lo sindical y lo étnico (migraciones al Norte), puesto que esos nuevos derechos son la reivindicación de la vieja clase obrera y sus directos descendientes y beneficiarios. Por otra parte, presupone el fracaso del Estado nación de ofrecer vías saludables a los trabajadores y su conciencia en tal fracaso (Wallerstein, 2004:464-474). Dicho en términos de Wallerstein (1996), si el Estado nación ha venido sufriendo un estruendoso declive, esto se debe más a la conciencia de los trabajadores sobre su fracaso que a la fuerza invisible del mercado global, que muy a su pesar, requiere de la intervención del Estado.

En este trabajo, sin embargo, se asume que el sistema internacional contemporáneo, por el contrario, es el resultado de una "historia de la expansión del moderno sistema-mundo hasta sus actuales dimensiones globales a través de una serie de reorganizaciones de sus fundamentos" (Arrihi y Silver et. al. 2001:29) ${ }^{4}$. Para efectos de este estudio, se entienden las relaciones internacionales como un sistema en el cual interactúan diversos órdenes ${ }^{5}$.

${ }_{4}^{4}$ El modelo de Wallerstein de transiciones hegemónicas desconoce, según Arrighi y Silver, que los cambios sistémicos se pueden ocasionar como factores endógenos al sistema, y asume una posición ciertamente neorrealista. Aquí se seguirá el modelo propuesto por Arrighi y Silver que "describe un ciclo hegemónico [...] resultado de la interacción de dos tipos diferentes de liderazgo que definen conjuntamente las situaciones hegemónicas". Por tal razón, con la suficiente evidencia histórica, demuestran que por el contrario, el Estado nacional tiende a impulsarse, emulación originada por el propio sistema y que proporciona al Estado individual "el impulso motivacional necesario para movilizar las energías y recursos precisos para la expansión", sea la potencia hegemónica o sus competidores (2001:36).

${ }^{5}$ Como disciplina científica, las relaciones internacionales se fundamentan en un "análisis político y económico de la sociedad, cuyo continuo punto de partida y de referencia lo 
La idea cardinal de este trabajo es que el actual orden (desorden), mundial es una secuencia de diversos momentos históricos que evolucionaron hasta convertirse en lo que es la Sociedad Internacional contemporánea. El actual desorden es la fase más avanzada de esta era., lo cual supone que las relaciones internacionales hacen parte de una matriz, la de la modernidad que las sistematiza y las configura dentro de un orden basado en las premisas básicas de aquel movimiento ${ }^{6}$. Normalmente estas situaciones y momen-

constituyen aquellas leyes que determinan el proceso de producción y reproducción de nuestra época, la edad histórica de la Revolución Capitalista" (Krippendorff, 1985:25). El sistema internacional, en sentido histórico, sirve como referente en el estudio de las relaciones internacionales para compararlas entre sí y generar un cuerpo de significantes reales demostrables empíricamente. Emite un patrón general de relaciones que configuran un orden, en un escenario general donde se suceden los fenómenos internacionales (Barbé, 1995:113-117; del Arenal, 1993).

En el caso de que pudiera determinarse una "filosofía del orden" moderna, ésta se identificaría con la idea reguladora del saber totalizado. Desde Kant o Fichte, el Weltanschauung de los seres -del filósofo, más bien- concibió la existencia de un mundo, su entorno, historia y la diferencia con otros, hasta el punto de que el orden determinado o sus posibilidades de existencia, se convirtieron en una simple idea (Sartre, 1963), o en una periodización arbitraria que descartaría los diversos intereses o conflictos de clases en una determinada época o sociedad, como el nacionalismo o el imperialismo acendrado después de 1890 (Hobsbawm, 1997). Sin embargo, la existencia de un cúmulo de valores en un orden dado se suscita precisamente en una premisa, la de la Historia concreta. Mas las posibilidades de existencia, la trascendencia o el ideal de un orden sólo podrían ser perceptibles en la medida en que también por medio de la Historia- se conjuguen un sinfín de acontecimientos o sea las revoluciones o la Guerra. (Al referirse a la función de la historia, Fukuyama (1992:29-30), insinuaba de la manera más hegeliana posible, que ésta permitía establecer la existencia de una "orden con sentido en la marcha de los acontecimientos humanos").

En este ensayo, se verá que el estudio del orden es el que permite captar una realidad social que imbrica una evolución de forma sistemática que se relaciona con un entramado de procesos y lógicas propios de la Historia.

${ }^{6}$ La consolidación de un orden aburguesado y capitalista durante los años 1789-1848 creó las bases de un orden nuevo que parecía perdurable e inmodificable, hasta que un siglo después las revoluciones sociales, las guerras coloniales y el socialismo real impuesto por la URSS supusieron la contradicción del sistema imperante (Hobsbawm, 1994, 1997). No obstante, una perspectiva más conservadora atendería tal "contradicción" como una fase distorsionada del capital-ismo, hasta el punto de catapultarlo con una ligereza conceptual considerada como el "fin de la historia" (ver Fukuyama, 1992; Hobsbawm, 1994; Arrighi y Silver, et. al., 2001). Desde las postrimerías del siglo XVII, tanto la clase burguesa ascendente como las monarquías respaldadas en ésta, proyectaron un idearium con los patrones básicos de la nueva era: un sistema político, económico y militar abuerguesado, soportado por una 
tos se desarrollan en diversos períodos que descubren la existencia de varios órdenes históricos -en plural-, que se pueden sintetizar en cuatro órdenes dinámico-estáticos y tres de transición y caos que en común, acentúan una premisa histórica, en la que los órdenes se sacuden unos de otros a raíz de una guerra o revolución. Observar órdenes históricos y potencias hegemónicas (cuadro 1) ${ }^{7}$ :

CUADRO 1. ÓRDENES HISTÓRICOS Y POTENCIAS HEGEMÓNICAS

\begin{tabular}{|l|l|}
\hline $\begin{array}{l}\text { Sub-Orden mundial westfaliano } \\
\text { (1648-1780). }\end{array}$ & $\begin{array}{l}\text { Provincias Unidas-Francia- } \\
\text { Gran Bretaña }\end{array}$ \\
\hline $\begin{array}{l}\text { Sub-Orden mundial de transición } \\
\text { de corte napoleónico (1780-1815). }\end{array}$ & Francia-Gran Bretaña-Rusia \\
\hline $\begin{array}{l}\text { Sub-Orden mundial del Congreso } \\
\text { de Viena (1815-1919). }\end{array}$ & $\begin{array}{l}\text { Gran Bretaña-Prusia (luego } \\
\text { Alemania)-Estados Unidos }\end{array}$ \\
\hline $\begin{array}{l}\text { Sub-Orden mundial de transición } \\
\text { de corte wilsoniano (1916-1945). }\end{array}$ & $\begin{array}{l}\text { Gran Bretaña-Estados Unidos- } \\
\text { URSS }\end{array}$ \\
\hline $\begin{array}{l}\text { Sub-Orden mundial del sistema de } \\
\text { naciones unidas o sistema de la } \\
\text { ONU (1945-1970). }\end{array}$ & Estados Unidos-¿URSS? \\
\hline $\begin{array}{l}\text { Nuevo (des)Orden mundial } \\
\text { (transición o caos, de 1970-1990 } \\
\text { en adelante) }\end{array}$ & $\begin{array}{l}\text { ¿EstadosUnidos?-¿China?- } \\
\text { ¿Islam?-¿Multinacionales? }\end{array}$ \\
\hline
\end{tabular}

cada vez más creciente economía del «capital», la expansión colonial, una nueva educación, racional y laica, y los parámetros culturales propios de una civilización universal universalizante-. Más importante aún, el patrón básico del nuevo orden estableció los lineamientos de las relaciones entre los Estados desde la óptica de una lisa y llana política del poder (Schwarzenberger, 1960).

${ }^{7}$ Wallerstein (2004:412-413), asume que "tales períodos de hegemonía real, en que la capacidad de la potencia hegemónica de imponer su voluntad y su 'orden' a otras potencias importantes no enfrenta desafíos serios, han sido relativamente cortos en la historia del sistema mundial moderno". Según este autor, cada período de hegemonía real en la historia del sistema ha sido de veinticinco años, y reseña tres casos: Provincias Unidas en el siglo XVII, Gran Bretaña en el XIX y Estados Unidos en el XX. 
Los diferentes escenarios y actores que regulan el nacimiento, desarrollo y decadencia de un orden están sujetos a una referencia temporal ${ }^{8}$. Para entender la dimensión temporal de la Sociedad Internacional se debe considerar que los períodos de paz y guerra que se desarrollan en su seno, se suscitan en un tiempo invariable, impredecible que alteran profundamente la estructura de un orden dado ${ }^{9}$. Sea cual sea la dimensión del fenómeno internacional que el estudioso esté tratando, empero, la dimensión temporal de todo orden, como en la naturaleza, nace, se desarrolla, decae y desaparece. La temporalidad nos es útil para establecer la evolución de un orden -en singular- con su ciclo de vida particular (del Arenal, 1993), o sus hegemonías (Wallerstein, 2004:412-428) ${ }^{10}$.

Pero ¿cómo sucede el cambio de un orden a otro, si se acepta que un orden está en permanente ebullición, si de estático pasa a ser dinámico? Puede

\footnotetext{
${ }^{8}$ La más o menos nueva disciplina de la Historia de las Relaciones Internacionales cree que la preocupación central de los actores internacionales en el instante que comienzan a (re)crear un orden trata acerca de situaciones conflictivas de carácter internacional:

“La formulación y aplicación de este orden será el objeto principal de interés de los llamados 'arquitectos de la diplomacia internacional' (Napoleón, Metternich, Bismarck, HItler, Kissinger, etc.). Representantes de las grandes potencias, un "directorio del poder", que bien en conferencias o congresos internacionales -Westfalia, Viena, Berlín, París, Yalta o Potsdam-; mediante tratados o acuerdos -Cuádruple Alianza, Troppau, París, San Stéfano, Algeciras, Versalles, Locarno o Helsinki-; u organizaciones internacionales -Sociedad de Naciones, ONU, OTAN, OSCE, etc.-, plantean cuál ha de ser la estructura de poder, qué mecanismos deben utilizarse para su mantenimiento y qué medios se emplearían en caso de ruptura del orden establecido" (Pereira, 2001:53).
}

${ }^{9}$ Algunos fenómenos micro que se focalizan en un espacio reducido, local o regional, se desplazan en temporalidades de corto, medio y largo plazo que no alteran en lo fundamental un orden. Tal es el caso de las relaciones entre dos estados, la política exterior y sus efectos sobre una región o las presiones ejercidas por un organismo económico internacional sobre un Estado.

${ }^{10}$ Siguiendo a Wallerstein, se entiende por hegemonía en el sistema internacional "por definición la existencia de una potencia cuya situación geopolítica le permite imponer una concatenación estable de la distribución social del poder que posibilita un período de 'paz', entendida como ausencia de confrontación militar entre las grandes potencias". Además, "un período de hegemonía requiere, y al mismo tiempo genera, 'legitimidad', entendiendo por tal, la sensación por parte de los principales agentes políticos (incluidos grupos amorfos como las 'poblaciones' de los distintos Estados), de que el orden social existente es el mejor posible o de que el mundo ('la historia'), se mueve continua y rápidamente hacia ese orden social". 
llegar a confundirse la transición de un orden a otro, si está siempre inmersa en una temporalidad de largo plazo o lo que es lo mismo, muchas veces suele confundirse largo plazo con transición. En este estudio, se prefiere considerar que las transiciones se dan usualmente en los momentos que caracterizan la existencia de los cambios profundos que sin más, están condicionados por la acumulación de acontecimientos y cambios sociales que se estacionan en un momento dado -tiempo largo- del ordenamiento internacional. Pero la transición de un orden a otro no queda supeditada necesariamente a una temporalidad larga, sino que por el contrario, se sucede por la emergencia de un cambio acelerado y corto, producto de los factores históricos. Existen también momentos en los cuales, un orden de transición se alarga en el tiempo y llega a confundirse como un orden en "desarrollo", autónomo y claramente establecido (Wallerstein, 1998, 2004; Arrighi y Silver et al. 2001; Abu Lughod, 1989), pero que en los interludios anteriores o posteriores a los veinticinco o treinta años de una hegemonía mundial, reflejan sendos momentos de bifurcación ${ }^{11}$.

En este trabajo se intenta desarrollar el nuevo (des)orden mundial de transición que comenzó en c.1970-1990 y que aparentemente continuará en caos hasta 2025-2050. En términos generales, no existe consenso sobre las características y las interpretaciones del orden que emerge desde 19701990. En tal sentido, se hizo una propuesta que induce a pensar que existe un punto equilibrado entre el nuevo-orden-des-orden-mundial donde confluyen los tres componentes más importantes del sistema internacional (en especial el debate sobre la hegemonía norteamericana). En este ensayo no se pretende ofrecer vías alternativas para la construcción de un orden justo; tampoco aprovechar las condiciones de la bifurcación actual para

${ }^{11}$ Casi todos los autores sistémicos coinciden en afirmar que durante los períodos de caos o transición, la potencia hegemónica en declive -paulatino y lento- reinventa o trata de amortiguar la fuerza que arrasa su poderío. Por ejemplo, Wallerstein (2004:476-478), dice que Estados Unidos respondió "a esa pérdida de hegemonía" (1968-1973) de dos formas: la primera, desde Nixon hasta Bush padre, consistía en el empleo, por medio de alianzas, "del puño de hierro con guante de terciopelo", es decir, la supuesta cooperación y liderazgo de todos, un equilibrio de poder en el cual se abría más participación a Japón y Europa Occidental (por ejemplo: el G7, la Comisión Trilateral y el apoyo a la creación de una Europa unificada); la segunda, por medio del Consenso de Washington, la contraofensiva del neoliberalismo y las homogeneizaciones de las elites económicas del mundo. De tal forma, Estados Unidos junto con la estrategia militar de los halcones, emprendió la carrera para suavizar ante la opinión pública internacional, lo que sería su declive. 
REVISTA DE RELACIONES INTERNACIONALES, ESTRATEGIAY SEGURIDAD

sumergirse en una Utopística del tipo de Wallerstein en el sentido de una experiencia histórica que pueda dar visos para una nueva era. Se presentará más bien, una revisión de las dos interpretaciones que han pesado más en la coyuntura actual de caos y orden, tomando en consideración las propuestas derivadas o la revisión crítica ofrecida en lo que aquí se ha denominado "punto de equilibrio" en el Nuevo (des)orden mundial12.

\section{LA VISIÓN IDEALISTA DEL MUNDO NORTEAMERICANO}

Desde la doctrina Clinton, se anunciaba que la nueva misión de Estados Unidos era consolidar la democracia y abrir nuevos mercados. La vieja transacción idealista en la cual Estados Unidos tiene la idea altruista de congregar la internacionalización del derecho, se estrechaba con otra que afirmaba que el mundo no tenía más remedio que recibir una dosis justa del interés nacional norteamericano. Cualquiera de las dos, el hecho es que la estrategia militar seguía en el toldo. No sólo la amenaza planteada por los Estados hostiles del Tercer Mundo o "regímenes parias", sino por el posible surgimiento de un "oponente de potencia comparable" que pueda enfrentarse a Estados Unidos con casi las mismas posibilidades, generó sentimientos de temor y escepticismo. Por tal razón, aparecieron en escena presunciones tales como la del "Nuevo Orden Mundial", "Choque de Civilizaciones" y, la más reciente, pero no menos patética "Lucha contra el Terrorismo".

Al finalizar "teóricamente" la guerra fría, aparecieron algunos referentes paradigmáticos sobre la "nueva época". Apotegmas como el de "un sólo mundo", democrático y liberal; "dos mundos", de ricos y pobres; de una sociedad interestatal justa y equilibrada; o de caos y desorden, el del "choque de civilizaciones" parecía ser el más contundente para los idealistas norteamericanos. De las siete civilizaciones presentadas por Huntington (1997), la Occidental produjo un influjo determinante sobre las demás civilizaciones, a saber, la islámica, china, hindú, eslava, latinoamericana y africana. Huntington se lanza en ristre contra los teleólogos de la democracia liberal y universal y los arraigados defensores de la "cultura mundial" o globalizada, debido a que las múltiples doctrinas políticas y la existencia de

${ }_{12}$ Aunque no se hará una descripción detallada sobre lo que el autor concibe del sistema internacional contemporáneo, este aspecto lo pretende desarrollar en una segunda entrega de próxima publicación.

ORDEN, DES-ORDENYANTIORDEN MUNDIAL. Problemas de Relaciones Internacionales 
diversos centros culturales en el globo, no han fortalecido la creencia de una civilización universal (Fukuyama, 1992). A diferencia de Fukuyama, que cree que el capitalismo liberal triunfaba definitivamente desde la óptica norteamericana, Huntington arguye que la modernidad trastocó, aunque no de manera uniforme en algunas sociedades tradicionales, hasta el punto de convertirlas en regiones hostiles al mundo occidental (Huntington, 1997; Arrighi y Silver et al. 2001).

Además, la manera como Huntington da cuenta de la historia de las civilizaciones, y por ende de sus choques, se remite a una cuestión exclusivista de tipo cultural. Cree que las civilizaciones sufren un proceso de secularización producto de la coyuntura internacional de la posguerra fría, donde antes de esto las civilizaciones convivían en un estado modórrico. Sin embargo, poco da cuenta acerca de un posible choque antes de la caída del socialismo real. Dicho en otros términos, tal Choque de Civlizaciones no fue más que una propuesta de nueva guerra fría planeada por el gobierno norteamericano, en el caso de un posible auge de China o Rusia, de los estados parias o del remozado terrorismo a partir de 1995-1996 (Lewis, 2001).

Al derrumbarse la Unión Soviética, se tenía que buscar la forma de sostener la hegemonía norteamericana. Para los halcones y neoliberales norteamericanos, la fase transicional de caos tiene una secuencia hacia el desarrollo integral de Estados Unidos como potencia hegemónica universal. Paradigmático fue el bombardeo en Yugoslavia. La invasión a Afganistán e Irak son la continuación de la fase de hegemonía integral. Los atentados del 11 de septiembre de 2001 no son un hito fundador de una estructura nueva del orden, sino una coyuntura de lo mismo. La razón por la cual, el 11 de septiembre de 2001 tiene una importancia trascendental que va más allá de las víctimas que se escogieron y la vulnerabilidad del territorio y el corazón financiero norteamericanos es categóricamente, el terrorismo (Mann, 2004). Distintas versiones y tipologías recubren este fenómeno ${ }^{13}$, desde el terrorismo de Estado, el religioso, de los grupos de reivindicación nacional, el ecológico, hasta pasar por uno tan antiguo como la propia idea de terror, el de tipo psicológico. Aunque los problemas cruciales surgen con el fin de la II guerra mundial, cuando Estados Unidos tenía un poder aplastante, la responsabilidad por el bienestar del sistema mundial avizora un enemigo común con el terrorismo.

${ }^{13}$ En este ensayo serán englobadas dentro de la categoría del anti-orden. 
A cada región del mundo se le había asignado una función en la reconstrucción del orden, dentro de lineamientos que beneficiarían el poder corporativo y estatal de Estados Unidos (Wallerstein, 1998; Chomsky, 1997). A decir verdad, el temor norteamericano en vastas zonas del globo no se remitía a una confrontación bipolar con el enemigo comunista. Desde la Conferencia de Chapultepec en 1945, Estados Unidos comenzó una política sistemática de eliminación de programas nacionalistas, no por temor al comunismo, sino para evitar la difusión de ideas tan contrarias a su espíritu como aquéllas que aludían a la distribución de la riqueza (Chomsky, 1997, 2002). Los países periféricos y recién independizados comenzaron a ser parte del viacrucis neocolonial hacia Washington.

Pero las clásicas amenazas nacionalistas sólo fueron el telón de fondo de una situación significantemente peligrosa. Los poderes medios del Tercer Mundo se constituyeron en una amenaza desde el punto de vista militar, en la cual existen naciones capaces de desarrollar armas de destrucción masiva. Las armas nucleares fueron la pieza central de la estrategia de Estados Unidos en este período; pequeñas armas nucleares hechas a la medida para utilizarlas contra los parias, fueron también creadas para atacar a la Potencia (Mann, 2004; Wallerstein, 1998). Durante la administración Clinton, se recomendó que las armas nucleares estuvieran disponibles para utilizarlas como reacción preventiva. Disponibles o visibles para los adversarios era una fuente clásica de disuasión. Con la caída de la URSS, la cortina de humo se desvaneció, y mostró una cara discreta de la guerra. Nacionalismos más potencias medias regionales tenían la capacidad, al menos en la letra, de atacar las entrañas del orden. El eje del mal es una muestra de esta fusión diabólica de nacionalismo, terrorismo y armas de destrucción masiva.

El terrorismo no es la única categoría de análisis propia de esta fase de caos. Es, junto con las drogas, los derechos humanos y el medio ambiente, el objeto de estudio de una realidad presente. Aunque es la más importante, se hace pensando que la intervención norteamericana en todo el mundo es benévola. Lo que es bueno para Estados Unidos es bueno para el mundo. Esta alegoría es incitante e induce a pensar que si para sostener el orden hay que atacar el terror, pues se hace con terror. El terrorismo internacional está cobijado con la rúbrica del anti-orden mundial. Los que actúan bajo esta lógica -del terror- creen estar involucrados en un mundo de presión, dominación e intransigencia propias del orden global. Sus objetivos se encaminan a liberarse de ese estado de sumisión y a oponerse a los ejércitos impe- 
riales -ONU o Estados Unidos- de ocupación. Consideran que las prácticas ético jurídicas universales del Derecho Internacional General son ilegítimas, que están en desuso.

En balance, el terrorismo es el principal escenario en donde el orden neoimperial establece las reglas de juego desde 1996 ó incluso antes (Mann, 2004). En la medida en que desaparecen los viejos enemigos -ficticioscomo el comunismo, es necesario nutrir el paquete de modificaciones tácticas so pretexto de una política de continuidad de las grandes potencias. Es la ampliamente conocida "invención de Estados terroristas".

La defensa de los halcones y neoliberales del Departamento de Estado (entre ellos Joseph Nye), reposaba en que si bien desde finales de los 80 la incertidumbre se apoderó de todo, Estados Unidos emergió como el gran victorioso. Siguiendo a Tokatlián $(1992,1996)$, desde 1990 el sistema internacional pasa por un primer período de transición que después de 1996 se estabiliza por Washington ${ }^{14}$. Incluso críticos autores de la arrogancia norteamericana, como Chomsky $(1997,2002)$, creen que el periodo incrustado en el final de la guerra fría no es más que una continuación de lo mismo. Para este autor, el orden imperante después de 1990 se remite a una referencia hegemónica, consolidada por Estados Unidos mucho antes de esta fase. Chomsky, sin embargo, desconoce los momentos de caos y contradicciones que se generan en este momento. Esta hegemonía descansa en un tipo de régimen precario a largo plazo, con múltiples contradicciones (Tokatlián, 1992). Estados Unidos comprende que puede emplear su liderazgo para generar consenso. O en el peor de los casos, la dominación/ coerción aparece como la principal concatenación de su interés nacional.

La configuración de un nuevo ordenamiento internacional diseñado en Occidente y dirigido por Estados Unidos, originado por la caída de la URSS, la desaparición del socialismo real y el final de la guerra fría, se apropiaba del diseño de un "esquema de liderazgo" muy a pesar del supuesto declinar norteamericano (Tokatlián, 1992, 1996). Bastaría con recordar que por ser un momento de caos, era factible la posible extinción de Estados Unidos como potencia hegemónica. La reducción de su presupuesto militar, la

\footnotetext{
${ }^{14}$ Una fase de hegemonía mínima, caracterizada por la implementación de políticas neoliberales, las fuerzas de mercado como principio ordenador, dominación unilateral y distribución desigual de recursos.
} 
REVISTA DE RELACIONES INTERNACIONALES, ESTRATEGIAY SEGURIDAD

emergencia de posibles potencias alternativas, el descenso en la participación industrial mundial, entre otros factores, eran vocablos de muchos analistas. Durante las tres décadas posteriores a la II guerra mundial, la inversión militar de Estados Unidos se redujo del 50 al 25\%, mientras que su participación en las reservas monetarias internacionales tuvo un drástico descenso del 50 al 7\%. Después de una ligera recuperación entre los 80 y 90 , el tesoro norteamericano afrontó un angustioso "déficit presupuestal", en tres direcciones. Del gobierno federal se reportó un déficit de US 200 mil millones anuales; de la balanza comercial US 100 millones anuales al final de los 90, y casi US 1 billón en deuda pública proveniente de inversores extranjeros (Rochester y Pearson, 2000).

El optimismo de quienes pregonaron el declive estrepitoso de Estados Unidos fue efímero. Como arquitecto del mundo unipolar, se describe una perspectiva más comprehensiva de "sistemas globales" que combina los aspectos materiales e ideológicos de la hegemonía, ya sea mínima o integral (Tokatlián, 1992). Además de contar con más de una tercera parte del rubro de inversión militar mundial, los norteamericanos se aprestaron a consolidar una economía "global" con bases y capitales propios. Al exagerar sobre el declive norteamericano, casi nunca se tuvo en cuenta la emergencia de las economías europeas, japonesa y del sudeste asiático, por cierto jalonadas por Estados Unidos. Tampoco se incluían en los estudios de economía internacional, "curvas" que explicaran este declive, en tanto que descartaban las fusiones de capitales y los volátiles empréstitos extranjeros que sacudían el centro financiero norteamericano. Si la "curva" norteamericana mostró un descenso desde la década de 1970 -casi cien años después de relegar a Gran Bretaña, que sufrió la contracción de los precios y la demanda mundial de manufacturas- esto obedeció más a la expansión de las relaciones sociales de producción y la inversión de capitales norteamericanos dentro y fuera del país (Rochester y Pearson, 2000).

Para Tokatlián (1992), simultáneamente, se debe tener en cuenta que en un periodo de transición sobresalen tres factores: una compleja y rara mezcla del antiguo y el nuevo orden; el desorden; y la trascendencia de los fundamentos encontrados en el sistema global que podrían permitir a la potencia dominante, emerger triunfante del caos. Se destacan, de este último, los siguientes aspectos: primero, la suposición que daría paso a un mundo multi-céntrico, donde el Estado-nación perdería protagonismo; la aparición de múltiples actores internacionales, diferentes al Estado nacional; 
segundo, si las relaciones de mercado marcan el más alto auge de preponderancia desde hacía varias décadas, la tradicional diplomacia militar, los asuntos de la guerra y la paz llegan a equipararse con los nuevos parámetros del neoliberalismo; tercero, la globalización liberalizante y la regionalización a ultranza llegan a un punto álgido en el escenario de posguerra. Sin embargo, se hizo evidente la desaparición de las homogeneidades regionales en los países en vía de desarrollo, como en América Latina; cuarto, concebido el viejo paradigma marxista en el cual las relaciones internacionales se basaban en situaciones de dominación de centro-periferia, con el surgimiento de actores semiperiféricos o poderes regionales, habría espacio para maniobrar al tranzar una política exterior autónoma, lo cual significa que los conceptos poderío y poder en las relaciones internacionales tendrían que redefinirse. Si antes se hablaba de poderío militar-poder nuclear y poderío energético-poder petrolero, ahora surgen el poderío científico-poder tecnológico y el poderío natural-poder ambiental; quinto, el saber y el conocimiento científico y tecnológico son la base del progreso nacional, asunto que tenía vigor en los diversos momentos nacionalistas de América Latina y Asia en todo el siglo XX; sexto, los temas más relevantes de la agenda global no se vislumbran como nuevos: medio ambiente, drogas, migraciones, derechos humanos, pobreza, equidad y terrorismo (Tokatlián, 1992). Asuntos todos que estarían dirigidos por Washington, y darían lugar a una autonomía relativa de las viejas regiones periféricas o aliados de Estados Unidos (Tokatlián, 1996).

En forma paralela, a partir de 1990 comienza a resbalarse la doctrina de los "regímenes parias" por todo el Departamento de Estado. Con la "estrategia de defensa regional" aprobada por el Pentágono, la Guerra del Golfo se planteó como el precedente del tipo de conflictos que tendrían que enfrentar más adelante, conflictos regionales en los cuales se encontraban con sujetos armados de valor y una o más bombas atómicas. Los Estados parias son la antesala de los Estados terroristas. Son el voto que se requiere para vitalizar el presupuesto militar norteamericano cuando desaparece el enemigo comunista. Prioritario para Estados Unidos, sería una cuestión adornada por la Geopolítica: los recursos energéticos, las rutas comerciales del golfo, el mar Caspio y del mar de China, ricas en petróleo; Rusia y China, sin embargo, siguen siendo una amenaza para la seguridad de Estados Unidos en el medio plazo. Este potencial enemigo se diferencia de los Estados parias por representar una amenaza mucho mayor y que trasciende un simple escenario regional. 
El fundamento de la política y estrategia militar de los presidentes Clinton y Bush correrá por esta vía. Estados Unidos siguió desarrollando políticas de defensa -acción preventiva- contra las amenazas de potencias hostiles del Sur, y propende por mantener una estructura militar, capaz de enfrentar simultáneamente dos grandes conflictos regionales, sean en el golfo Pérsico, contra Irán o Irak, y otro en Asia Oriental, contra Corea del Norte. También es evidente que los estrategas norteamericanos visualizan escenarios diferentes como un conflicto con Moscú por los recursos del mar Caspio o una guerra con Pekín para garantizar la libertad de navegación en el mar de China. La preocupación central del Congreso norteamericano se centra más en la consecución del presupuesto adecuado para solventar estos futuribles.

\section{SISTEMA MUNDO MODERNO Y CAOS}

El furor que suscitó la caída del socialismo real, llevó a muchos autores a la idea de que se vivía en un mundo de cambios y caos. Abu Lughod, por ejemplo, vaticinaba por medio de un complejo entramado de relaciones económicas, nuevas relaciones capitalistas de dominación por el CentroPeriferia y de choque de civilizaciones, la vuelta al sistema mundo imperante en el siglo XIII, donde el centro (core), del sistema mundo era una combinación de civilizaciones islámica y chino-mongoles (Abu Lughod, 1989). Hobsbawm (1998:403), adujo que la historia "de los veinte años que siguieron a 1973 es la historia de un mundo que perdió su rumbo y se deslizó hacia la inestabilidad y la crisis", incluida la modernidad y lo que arrastra consigo (Estado nación, racionalismo y humanismo). Wallerstein (2004:412, 427), se aprestó a sentenciar con su habitual curva Kondratieff (fase B de declinación), que "hemos salido de la era de la hegemonía estadounidense en el sistema mundial (1948-1973), y entrado en una era posthegemónica".

En cuanto a la crisis histórica del Estado nación, algunos autores llegaron hasta el punto de sepultar y cederle el derecho de policía (presunción foucaultiana, por cierto), a una entidad supranacional, el Imperio (Hardt y Negri, 2000). David Held (2000, 2002), en el mismo sentido, pero en perspectivas diferentes, atribuyó esta crisis a los procesos de interconexión económica, política, legal, militar y cultural materializados en congregaciones regionales y la cada vez más atizada globalización, hasta llegar a una especie de "democracia cosmopolita". Un Imperio o una democracia cosmopo- 
lita tendrían el acecho insalvable en la agenda global del fenómeno de las migraciones, y esto, por lo demás, indica que las fronteras nacionales aún están herméticamente selladas para los trabajadores del Sur (Wallerstein, 1998:49-57). Estos aparecieron en escena como maquiladores o sujetos prestos a hacer los trabajos que los del Norte no quieren hacer. Existen organizaciones o grupos de presión que tildan a las potencias de fútiles empresas criminales que terminaron por alterar los sistemas políticos nacionales y los derechos de los trabajadores (Borón, 2002). Abogan por hacer entender a la humanidad que la globalización no puede ser entendida como la construcción de dos o tres Estados. En cualquiera de los casos, sin embargo, se desconoce que un orden mundial se construye como parte de una política deliberada de una/unas potencia/s. Estos grupos, por lo demás, cada vez se constituyen en una fuerza antagónica del orden, convirtiéndose en una especie de opinión pública mundial u organización de sociedades civiles prestas a la defensa de un orden social más justo ${ }^{15}$.

Por otra parte, la transición del orden que se suscita a partir de 1970-1990, que trastoca los cimientos del Estado nación, obedece a la fuerte desaceleración de la economía-mundo que se registró en los países industrializados (Hobsbawm, 1998). Las cifras que emergen a partir de 1970 dan cuenta más clara de esta situación. Los años posteriores a la crisis de los precios del petróleo ha revertido el proceso de crecimiento constante en la economía mundial, con un ligero ascenso a partir de 1995. Autores como Hirst y Thompson (Held, 2002), aducen que la integración de la economía mundial es significativamente inferior a la de finales del siglo XIX, la época del patrón oro. Los índices de integración mundial del comercio obedecen más a los impulsos imperiales de Occidente que a una inserción total de todas las naciones. Desde Washington o Tokio, por citar economías nacionales fuertes, se ha impulsado la liberalización del comercio como una práctica deliberada del nuevo imperialismo occidental. Esta presunción descarta la tesis globalista del debilitamiento del Estado nacional, pues una globalización concebida sin "fuerzas nacionales" es puro objeto de especulación. En este sentido, la globalización es un mero complejo de

${ }^{15}$ Las dimensiones del antiorden mundial también indican el auge de nuevos actores sociales en las relaciones internacionales, moda que se propagó en el medio académico desde 19601970. Siguiendo a Hofmann (1963:57), el tipo de poder que se suscita en el ámbito de la política exterior no es un mero instrumento de los Estados fundado en la creencia de que el poder por el poder es intrínsecamente suficiente. 
fuerzas integradas de diversas naciones poderosas. Es decir, los niveles de globalidad que se tienen hoy en día, obedecen más a parámetros internacionales -valga decir, naciones industrializadas- que globales (ver balance sobre las escuelas de la globalización en Held, 2002).

El modelo globalista se ha preocupado más por concebir la Sociedad Internacional como un modelo esencialmente sistémico, en el cual, los Estados nacionales son afectados directamente por las fuerzas del sistema global, sea cultural o económico. Pero sea cual sea la argumentación, lo cierto es que entre las décadas del 70 al 80, la economía mundial se contrajo en un $3 \%$, después de que las dos décadas posteriores a la guerra arrojaron cifras de crecimiento anual del 5\%. Para los "escépticos" de la globalización, como Callinicos (Held, 2002), este fenómeno obedeció a la lógica contraccionista de las economías nacionales imperiales. Pues cuando el punto focal de la economía mundial se centra en dos o tres regiones supraindustrializadas, automáticamente se descartan otras regiones, otrora insertas en el sistema de economía mundo, a la manera colonial. En rigor, es difícil concebir un sistema global compuesto por tres o cuatro economías nacionales. En otra perspectiva, los países industrializados se acusan entre sí, por trasladar sus energías productivas a regiones del mundo que ofrecen una baja carga salarial y tributaria (Wallerstein, 1996:31 ss). La nueva era de la economía se caracteriza por transigir de un simple formulismo de relaciones sociales de producción a la expansión de las fuerzas y relaciones del mercado a escala planetaria.

Las cifras del comercio mundial no fueron tan críticas (Hobsbawm, 1998:405 ss). A pesar de que el valor de las exportaciones aumentó entre 1950 y 1980 a unos US 2 billones, se niveló o se redujo en forma sensible a fines de esos años; al concluir los 90, aumentó a una cifra de US 4 billones. La era más avanzada del capital y la industrialización también muestran situaciones volátiles y a la vez dinámicas. Por ejemplo, si se alude al flujo del comercio internacional que por medio de la tecnología y los medios de comunicación ultra avanzados permite generar transacciones de centenares de millones de dólares diariamente, mediante la figura de "préstamos e inversiones", al mismo tiempo se refleja en algunos países, el alto nivel del riesgo financiero y la desigual distribución de la riqueza, y en otros, el reflujo positivo de capitales.

Al analizar las diferentes posturas, se obtiene una perspectiva más amplia de los criterios necesarios para una descripción rigurosa de la globalización. 
Se plantea entonces que la globalización puede comprenderse mejor como un proceso o serie de procesos diferenciados que revela una compleja intersección entre multiplicidad de fuerzas impulsoras como el cambio económico, tecnológico, cultural y político. Por ser proceso histórico, su análisis comprende una periodicidad amplia remitida a la modernidad y la expansión occidental de la industria, el colonialismo y el sistema internacional de Estados.

Si bien la globalización hace referencia a interconexiones regionales, las teorías existentes no están en capacidad de explicar procesos más delimitados o localizados. Una definición satisfactoria debe incluir dimensiones espaciales y temporales específicas, es decir, el alcance, intensidad, velocidad y repercusión de la globalización como un fenómeno que envuelve una transformación en la organización espacial de las relaciones y transacciones sociales locales, y viceversa. Como fenómeno cultural, la globalización genera flujos y redes transcontinentales o interregionales de cualquier actividad humana, y ésta, a su vez, es condicionante de la sociedad global. El ejercicio del poder es una fórmula que se adapta a los parámetros más evolucionados de la era del capital. Las formas históricas de la globalización y el poder están en función de los atributos y redes de relaciones y conexiones de dominación y hegemonía, su intensidad, velocidad y tendencias evolutivas de los flujos globales. Arrighi y Silver et al. (2001), prefieren dejar una reflexión bastante consensuada, que no admite Wallerstein (1996): el actual orden (caos), refleja el repunte esporádico de las altas finanzas en nombre de Estados Unidos, pero como en todos los ciclos capitalistas de transición, sólo representa un momento de ascenso temporal, como se verá más adelante.

Un momento transicional se combina, como se dijo atrás, de variaciones y confusas situaciones de la política internacional. En primer lugar, valdría preguntar cómo catalogar la guerra del golfo: ¿una guerra de la guerra fría?, ¿el inicio de una nueva fase de posguerra? Siguiendo a Wallerstein, la crisis del sistema se reflejó en primer lugar, en la revolución de Jomeini que luego fue seguida por la guerra del golfo. Ambos casos representaron el supuesto ascenso de los países históricamente marginados del sistema. La caída de la Unión Soviética forzó el planteamiento de nuevos escenarios, que sustentó a aparición de Estados Unidos en las zonas de influencia soviética. Un antiguo aliado de los comunistas vio por primera vez, desde el final de la guerra fría, el vaticinio norteamericano de lo que sería su política 
REVISTA DE RELACIONES INTERNACIONALES, ESTRATEGIAY SEGURIDAD

exterior en un futuro no lejano. Se trataba de Ilenar el vacío de poder que habían dejado los soviéticos en Asia Central y el Cercano Oriente. Pero no pasó de ahí.

Estados Unidos se mantuvo aislado de los conflictos hasta los bombardeos a Yugoslavia en 1996, cuando transita hacia una segunda fase caracterizada por la decisiva presencia norteamericana en cualquier resquicio del globo. Prueba de ello son las sucesivas invasiones a otras zonas como Somalia, Indonesia, Afganistán y los intempestivos bombardeos a Irak, durante el segundo lustro de los 90 (Geopolítica del Caos, 1998). El papel de Estados Unidos en la era de la globalización y del nuevo orden mundial como superpotencia, entrelaza una hipótesis que abarca un espectro confuso. ¿Está emergiendo una forma imperial de soberanía? o ¿es que el imperialismo remozado y tiranizante invade pueblos y destruye culturas, debido a la bandera democrática y neoliberal? (Mann, 2004). Desde la paz de Westfalia de 1648, basada en los principios de soberanía y autonomía de los Estados, el sistema internacional ha sido impelido permanentemente hacia una forma de Imperio (Hardt y Negri, 2002). Mann (2004), que prefiere Ilamarlo nuevo imperialismo, adujo que Estados Unidos tenderá a fracasar en los pueblos conquistados, por no implantar adecuadamente gobiernos de transición (building nation), al mejor estilo de las potencias colonizadoras del siglo XIX'16.

Después de una larga década de intermitencias militares, bombardeos y de los ataques sufridos el 11 de septiembre de 2001, Estados Unidos plantea una política exterior reformulada de la seguridad nacional, que prioriza el intervencionismo militar, propugna el ataque preventivo en la lucha frontal contra el terrorismo, en lugar de la contención y la disuasión. Por esta razón, los diferentes Estados considerados potencias terroristas o que apoyan a los terroristas, llamados también estados canallas que almacenan armas de destrucción masiva a las cuales acceden los terroristas, son el blanco de las políticas norteamericanas (Mann, 2004).

Más aún, para quienes todavía creen que la geopolítica estuvo en desuso después de 1990, basta con citar que el orden unipolar de "caos" ha sido

\footnotetext{
${ }_{16}$ Ver también la posición contraria que defiende Fukuyama (2004:139-172), cuando asume que Estados Unidos debe ser el líder indiscutible en los procesos legítimos de construir naciones en Asia, África o en cualquier lugar donde haya "gobiernos débiles" y hostiles.
}

ORDEN, DES-ORDEN Y ANTIORDEN MUNDIAL. Problemas de Relaciones Internacionales 
principalmente analizado con las herramientas de esta disciplina: cincuenta y nuevos conflictos que afloran o se congelan, guerras de secesión, civiles y fronterizas, intervención de grandes potencias para, por medio de la "ayuda humanitaria" o la intervención militar, solucionar situaciones de crisis y atenuar sus intereses en determinadas regiones (verbigracia, Asia Central e Irak). En algunos otros casos, las potencias permiten la incubación de esos conflictos, con los ejemplos patéticos de la Unita en Angola, los Khmers rojos en Camboya o las guerrillas y paramilitares en Colombia. Desde la década del 80, estos grupos han ido evolucionando de simples movimientos populistas o nacionalistas a grupos de poder que jalonan la política interna y exterior de los países involucrados. Su principal preocupación es geopolítica, pues asumen el control territorial de ciertas regiones o los recursos energéticos y minerales (El Atlas de Le Monde Diplomatique, 2003)

Además de Yugoslavia y el Medio Oriente (la guerra del golfo antes que el conflicto palestino-israelí), la atención del mundo se centró en el corazón de Asia, aunque con menos interés del público en general y del medio académico colombiano en particular. Pasando por los Estados que bordean las costas del mar Negro hasta llegar a la frontera china, los Estados transcaucásicos han estado en la mira de múltiples hombres de la burocracia, la política exterior, el sistema financiero y las petroleras rusas y norteamericanas.

Para los financistas e inversores occidentales, el petróleo del mar Caspio, el gas turkmenistano, el algodón uzbeco y el oro kirguiz adquieren una renovada importancia geopolítica. Además de ser un enclave geográfico que permite rodear toda Asia Central y convertir a Transcaucasia en un puente entre el mar Caspio y los mares abiertos -Océano Índico antes que el Mediterráneo-, sin involucrar a Rusia o Irán, la zona ha sido proclive a acentuar monopolios comerciales con capitales europeos o norteamericanos. Para los rusos, la cuestión ocurre por recuperar su vieja influencia en la región, revitalizar el paneslavismo y generar sentimientos proteccionistas en la población, ante la amenaza expansionista occidental. Aunque esta "lógica cultural" compagina con una de corte geopolítico, el problema para Rusia radica en el fracasado intento histórico de penetrar en Oriente Próximo. Turquía e Irán se convierten en un grave obstáculo para Europa, Rusia y Estados Unidos, que optarán por aliarse a uno u otro actor en contienda. A este tablero se le añaden los intereses chinos, pakistaníes e indios, con complejas relaciones fronterizas, pero con grandes posibilidades de convertirse 
en líderes regionales, capacidad bélica nuclear y un mercado potencial de varios miles de millones de consumidores.

A la vista de que Rusia no sería una potencia en decadencia estrepitosa, a los tecnócratas del Departamento de Estado y a los petroleros norteamericanos no les quedó otra alternativa que asumir un interés directo en la zona. El modelo turco, de ayuda y cooperación entre USA-Turquía, impuesto desde Washington para solventar el caos de la posguerra en las antiguas repúblicas soviéticas, fracasó. El interés de Estados Unidos se centró especialmente en dos frentes: reprimir el influjo iraní en Transcaucasia y sancionar a Azerbaiyán por el bloqueo que le impuso a Armenia. También se pensó que los antiguos miembros de la URSS consolidarían un frente unido de cooperación y ayuda mutua, capaz de proveer un mercado transparente y rutas comerciales libres hacia los mares, pero estos Estados enclaves sufrieron por los trastornos geopolíticos. Estados Unidos promovió leyes de bloqueo contra Azerbaiyán, pero tuvo a la vez, una actitud en la cual priorizó el petróleo azerbaijano. Tampoco tuvo reparo en asumir una posición antiarmenia -el Congreso- cotejando grupos iraníes que tenían acciones en petroleras de Armenia o Azerbaiyán. Las visitas constantes del presidente norteamericano G. W. Bush a los países de la antigua cortina de hierro y Asia Central, así como su permanente apoyo a los planes de democratización de la zona, son parte de la lógica geopolítica de la nueva era. En este camino, se puede nombrar el apoyo de Polonia o Bulgaria a Estados Unidos en la invasión a Irak (2003), el viraje hacia gobiernos prooccidentales (Ucrania o los países Bálticos), y el rechazo a la influencia rusa en los asuntos internos de los Estados (Kirguistán).

Mientras que para Europa, los intereses se concentran más en los recursos de Georgia y para Rusia en los de Chechenia, lo cierto es que la presencia de Washington en la zona, es cada vez más decisiva. Más de dos lustros han necesitado los norteamericanos para llenar el vacío de poder que dejó la URSS y fue asumido débilmente por la Comunidad de Estados Independientes (CEI). Por el hecho de ser el segundo productor de petróleo y gas mundial, Rusia es considerada pieza clave de la columna del tablero en el juego de la política mundial y la geopolítica. Tiene también la ventaja geoestratégica de tener un territorio todavía inmenso que obliga a Estados como Kazajstán o Turkmenistán a trasportar su petróleo "caspiano" por territorio ruso, hacia comarcas ucranianas o georgianas (Geopolítica del Caos, 1998).

ORDEN, DES-ORDEN Y ANTIORDEN MUNDIAL. Problemas de Relaciones Internacionales 
Rusia se encuentra en la encrucijada de adaptar parámetros democráticos muy depurados, exigencia que se hace palpable cada vez que el mandatario ruso $\mathrm{V}$. Putin se reúne con su homólogo norteamericano G. W. Bush. La eliminación de programas de energía atómica, los altos índices de corrupción, los derechos humanos, los bloqueos permanentes a los antiguos países soviéticos, las mafias y el narcotráfico, entre otros factores, son las principales herramientas de uno y otro para autominimizar su política exterior referente a Asia Central. Mientras que Rusia le exige a Estados Unidos no intervenir en sus asuntos internos, con lo cual refuerza la idea de que aquél todavía tiene margen de maniobrabilidad, Estados Unidos ve en estos aspectos, la principal fuente de amordazamiento para su antiguo rival.

\section{CONCLUSIONES}

¿Existe un Nuevo Orden consolidado?, ¿Se podría hablar de una potencia hegemónica -Estados Unidos- que acaso concibe las esferas de las interacciones internacionales en una sociedad multipolar? En este trabajo se vio que desde fines de la década de 1980, finalizó la bipolaridad mundial (o mejor, de la hegemonía norteamericana), pero debido a un futuro incierto. Es decir, no existió unanimidad respecto de cual sería n definitiva su reemplazo. Por tal razón, fue preciso aclarar acerca de los períodos de transición, crisis y desarrollo, cuándo un "orden" es esencialmente histórico. Un orden se construye históricamente, tomando como referente la pretensión de la realización humana sustentada en el pasado; un orden, además de ser la figuración -o configuración- de la narración histórica, de los filósofos o pensadores de una época determinada, también es el resultado de una sociedad real con personas de carne y hueso que son (o deberían ser), conscientes de su condición de "seres históricos". Por lo demás, es posible que se suscite en su propio seno, las contradicciones que llevarán a algunos actores del orden a promover la existencia de un orden nuevo (Schwarzenberger, 1960:634-635). El orden, de otra manera, es la proyección de una idea que descarta la mayoría de las veces, el pragmatismo inherente a la constatación histórica. Pero debido a que la idea de que las relaciones sociales de tipo internacional estén inmersas en una relación histórico-universal, diría Schwarzenberger (1960:635), que la "tarea más difícil y responsable de la crítica [...] es juzgar si es factible un proyecto de orden internacional". 
Entonces, un orden mundial ${ }^{17}$ es una estructura de poder particular, esto es, internacional, en la cual coexisten un conjunto de actores que gobiernan la Sociedad Internacional, establecen un conjunto de normas, reglas y mecanismos -sistema- que pretenden afianzar la estabilidad y evitar la anarquía, buscar la seguridad y el equilibrio entre los actores, y en definitiva llegar a una paz idealizada. Un orden mundial también es consecuencia de su propia carga de referentes simbólicos que da pie para creer que un orden es creado y creador (teoría de sistemas). A la vez. La preocupación central de los actores internacionales en el instante que comienzan a (re)crear un orden, se centra en situaciones conflictivas de carácter internacional. Sin embargo, al suponer que la matriz histórica del sistema reposa sobre la misión de civilizar a los pueblos que no están al abrigo del orden, un tipo de Sociedad Internacional dominante choca permanentemente con los distintos tipos de culturas o nacionalismos imperantes en una época. Un permanente caos y desorden rechina a los organizadores del orden en la medida en que tratan de transmitir valores internacionales dentro de un marco cultural deforme.

Con el favor de la invasión a Afganistán, y la segunda a Irak, se puede traslucir que está ocurriendo la consolidación de un Nuevo Orden Mundial, hegemónico y unilateral (visto así por los idealistas defensores de la hegemonía norteamericana). Pero también cabe anotar que una visión más sistemática de la Sociedad Internacional presenta al sistema con la misma originalidad que en períodos anteriores, pero de una forma reorganizada o reformulada. Por ejemplo, la universalidad del comercio, las ideas, el intercambio de moneda por zonas de frontera y civilización, etc., son prolegómenos de esta situación (Aron, 1994:129-130). Las bases para un nuevo siglo de dominio norteamericano están también en el supuesto del monopolio de productos de información y cultura, de procedencia norteamericana o hiperglobalizada. La tecnología, los medios de comunicación avanzados, las altas finanzas y la infraestructura militar moderna son sin embargo, elementos para poder entender que incluso una potencia hegemónica está en permanente rivalidad o competencia con otras similares, asunto éste que se explica mejor desde el punto de vista sistemático (sólo una hegemonía puede sostenerse en la medida en que existan unidades específicas que

\footnotetext{
${ }^{17}$ El término aparece en el Japón y la Alemania de la segunda Guerra, y remozado por Estados Unidos en 1990, augurando la aparición de un "orden de posguerra". La historia del término "orden mundial" en Pereira (2001); Rochester y Pearson (2000).
} 
tengan la misma potencia comparable, y, luego, competitiva y con la capacidad de desplazarla). Por más que Estados Unidos maneje una dominación sin problemas, el hecho es que ésta depende del apoyo de sus socios. Con este objetivo se configura la economía mundial, Ilevando a cabo una coalición entre los intereses gubernamentales, militares y comerciales. Pero las respuestas a los importantes interrogantes que plantea el cambio de escenarios, y el planteamiento de otros nuevos, son desafío y preocupación constante de los estudiosos de las relaciones internacionales.

\section{BIBLIOGRAFÍA}

ABU-LUGHOD, J. (1989). Before European hegemony. The World System A.D. 12501350. Oxford: University Press.

ARON, R. (1994). Los últimos años del siglo. Barcelona: Planeta Agostini.

ARRIGHI, G. y BEVERLY, Silver et al. (2001). Caos y orden en el sistema-mundo moderno. Madrid: Akal.

Autores varios (1998), Geopolítica del Caos. En: Le Monde Diplomatique (edición española). Temas de Debate. Madrid.

BARBÉ, E. (1995). Relaciones Internacionales, Barcelona: Tecnos.

BORÓN, A. (2002). Imperio \& Imperialismo. Una lectura crítica de Michael Hardt y Antonio Negri. Buenos Aires.

CALDUCH CERVERA, R. (1991). Relaciones Internacionales. Madrid: Ciencias Sociales.

CHALIAND, G. (2004). Atlas del Nuevo Orden Mundial. Barcelona: Paidós.

CHOMSKY, N. (1997). El Nuevo Orden Mundial (y el viejo). México: Crítica.

_-_—, (2002). La estructura emergente del orden mundial. Universidad Nacional de Colombia. Bogotá.

DEL ARENAL, C. (1993). Introducción a las Relaciones Internacionales. Madrid: Tecno. 
DEUSTSCH, K. (1968). El análisis de las relaciones internacionales. Buenos Aires: Paidós. .

El Atlas de Le Monde Diplomatique (2003). Edición española a cargo de Gilbert Achcar et al. Madrid.

FUKUYAMA, F. El fin de la historia...

. La construcción del Estado. Hacia un nuevo orden mundial en el siglo XXI. Barcelona: Ediciones B.

HARDT, M. y NEGRI, Toni (2000). Imperio. Buenos Aires: Paidós.

HELD, D. (1997). La democracia y el orden global. Del Estado moderno al gobierno cosmopolita. Buenos Aires: Paidós Iberoamérica.

et al. (2002). Transformaciones globales. Política, economía y cultura. Buenos Aires: Oxford.

HOBSBAWM, E. (1994). Historia del siglo XX. Buenos Aires: Crítica.

. (1997). La era de la Revolución, 1789-1848. Buenos Aires: Grijalbo.

. (1998). La era del imperio. 1875-1914. Barcelona: Crítica.

HUNTINGTON, S (1997). El choque de civilizaciones y la reconfiguración del orden mundial. Barcelona: Paidós.

KRIPPENDORF, E. (1993). El sistema internacional como historia. Introducción a las relaciones internacionales. Traductora Angelika Scherp. México: Fondo de Cultura Económica.

LEWIS, B. (2001). Las raíces de la ira musulmana. Fundamentalismo y atentados terroristas contra Estados Unidos. Letras Libres.

MANN, M. (2004). El imperio incoherente. Estados Unidos y el nuevo orden internacional. Barcelona: Paidós.

OHMAE, K. (1997). El fin del Estado-Nación. El ascenso de las Economías Regionales. Santiago de Chile: Andrés Bello.

ORDEN, DES-ORDEN YANTIORDEN MUNDIAL. Problemas de Relaciones Internacionales 
PEARSON, F. y ROCHESTER, Martin. (2000). Relaciones Internacionales, Situación Global en el siglo XXI. 4 ed. Bogotá: McGraw-Hill.

PEREIRA, J. (2001). El estudio de la sociedad internacional contemporánea. En: Historia de las Relaciones Internacionales. Coordinación de Juan Carlos Pereira. Barcelona: Ariel.

ROSENAU, J. (1990). Turbulence in World politics: a theory of change and continuity. Princeton: University Press.

SARTRE, J. P. (1960). Crítica de la razón dialéctica. T. 1. Buenos Aires: Losada.

SCHWARZENBERGER, G. (1960). La política del poder. México: Fondo de Cultura Económica.

TOKATLIAN, J. (1992). Neoliberalismo y política mundial. Dilemas y disyuntivas para la política exterior colombiana. En: Foro, 18, septiembre. Santafé de Bogotá.

-C- . (1996). Posguerra Fría y Política Exterior: de la autonomía relativa a la autonomía ambigua. En: Análisis Político, 28. Mayo-agosto. Santafé de Bogotá.

Wallerstein, I. (2004), "Capitalismo histórico y movimientos antisistémicos. Un análisis de sistemas-mundo". Madrid: Akal.

————. (1996), Después del liberalismo. México: Siglo XXI.

-_-_. (1984), El moderno sistema mundial. El mercantilismo y la consolidación de la economía mundo europea, 1600-1750. México: Siglo XXI.

_—_-, (1998), Utopística o las opciones históricas del siglo XXI. México: Siglo XXI. 